\title{
ARTICLE
}

Received 12 Oct 2013 | Accepted 28 Mar 2014 | Published 13 May $2014 \quad$ DOl: 10.1038/ncomms4749

\section{Two-stroke scooters are a dominant source of air pollution in many cities}

\author{
S.M. Platt ${ }^{1}$, I. El Haddad ${ }^{1}$, S.M. Pieber ${ }^{1}$, R.-J. Huang ${ }^{1}$, A.A. Zardini ${ }^{2}$, M. Clairotte ${ }^{2} \dagger$, R. Suarez-Bertoa ${ }^{2}$, P. Barmet ${ }^{1}$, \\ L. Pfaffenberger ${ }^{1}$, R. Wolf ${ }^{1}$, J.G. Slowik', S.J. Fuller ${ }^{3}$, M. Kalberer ${ }^{3}$, R. Chirico ${ }^{1} \dagger$, J. Dommen', C. Astorga ${ }^{2}$, \\ R. Zimmermann ${ }^{4,5}$, N. Marchand ${ }^{6}$, S. Hellebust ${ }^{6}$, B. Temime-Roussel $^{6}$, U. Baltensperger $^{1} \&$ A.S.H. Prévôt ${ }^{1}$
}

Fossil fuel-powered vehicles emit significant particulate matter, for example, black carbon and primary organic aerosol, and produce secondary organic aerosol. Here we quantify secondary organic aerosol production from two-stroke scooters. Cars and trucks, particularly diesel vehicles, are thought to be the main vehicular pollution sources. This needs re-thinking, as we show that elevated particulate matter levels can be a consequence of 'asymmetric pollution' from two-stroke scooters, vehicles that constitute a small fraction of the fleet, but can dominate urban vehicular pollution through organic aerosol and aromatic emission factors up to thousands of times higher than from other vehicle classes. Further, we demonstrate that oxidation processes producing secondary organic aerosol from vehicle exhaust also form potentially toxic 'reactive oxygen species'.

\footnotetext{
${ }^{1}$ Laboratory of Atmospheric Chemistry, Paul Scherrer Institute, $\mathrm{CH}-5232$ Villigen, Switzerland. ${ }^{2}$ European Commission Joint Research Centre, Institute for Energy and Transport, 21027 Ispra, Italy. ${ }^{3}$ Centre for Atmospheric Science, Department of Chemistry, University of Cambridge, Cambridge CB2 1EW, UK. ${ }^{4}$ Cooperation Group comprehensive molecular analytics/Joint Mass Spectrometry Centre, Helmholtz Zentrum München, 85764 Neuherberg, Germany. ${ }^{5}$ Chair of Analytical Chemistry/Joint Mass Spectrometry Centre, Institute of Chemistry, University of Rostock, 18051 Rostock, Germany. ${ }^{6}$ Aix Marseille Université, CNRS, LCE FRE 3416, 13331 Marseille, France. †Present addresses: INRA, UMR Eco and Sols, 2 Place Pierre Viala, 34060 Montpellier, France (M.C.); Italian National Agency for New Technologies, Energy and Sustainable Economic Development (ENEA), UTAPRAD-DIM, Via E. Fermi 45, 00044 Frascati, Italy (R.C.). Correspondence and requests for materials should be addressed to A.S.H.P. (email: andre.prevot@psi.ch).
} 
$\mathrm{P}$ articulate matter (PM) damages health ${ }^{1}$ and affects climate $^{2}$. Road vehicles are a significant source of PM, particularly in urban areas. A number of recent studies have shown that a large fraction, possibly the largest, of vehicular PM is secondary organic aerosol (SOA) produced via atmospheric oxidation of precursor gases in the exhaust ${ }^{3-5}$. Thus, understanding vehicular air pollution requires an assessment of SOA formation from different vehicle types. Two-stroke (2S) scooters (powered two-wheeled vehicles with engine displacement $\leq 50 \mathrm{~cm}^{3}$ ) are popular globally, particularly in Asia, Africa and Southern Europe. Despite being high emitters of primary $\mathrm{PM}^{6,7}$, regulations for scooters are generally less stringent than for other vehicles, for example, in Europe having reached Euro $5 / \mathrm{V}$ (a fifth tranche of regulations), for passenger cars and trucks, versus only Euro 2 for scooters (see Supplementary Table 1 and ref. 8). Accordingly, a scientific report to the European Commission suggests that scooters will emit more volatile organic compounds (VOCs) than all other vehicles combined in Europe by 2020 (ref. 9). Furthermore, high PM levels and toxic aromatic hydrocarbons, important SOA precursors ${ }^{10}$, have been observed in many cities, especially in Asia ${ }^{11}$. Globally, organic aerosol (OA) dominates PM, with SOA accounting for the largest fraction ${ }^{4}$.

Here we show that $2 S$ scooters emit significant amounts of primary organic aerosol (POA), aromatic VOCs and also produce significant SOA. We use the term 'asymmetric polluter' to describe these vehicles as their emission factors (EFs) and evidence from air quality measurements before and after bans on scooters in Asian cities suggest they may dominate vehicular pollution despite their relatively small numbers. Chemical analysis of the emissions shows that SOA is mainly produced via photo-oxidation of aromatic VOCs, present in gasoline, from the exhaust. This shows that the known issue of incomplete fuel combustion during the $2 \mathrm{~S}$ cycle is also responsible for SOA formation. Finally, we present the first online measurements of aged exhaust showing that SOA formation also produces reactive oxygen species (ROS) with potentially detrimental effects on our lungs.

\section{Results}

Emission Factors. We investigated POA emissions and SOA formation from $2 S$ scooters and their potential health effects. The oxidation of VOCs in $2 \mathrm{~S}$ scooter emissions produces significant SOA (g carbon (C) $\mathrm{kg}^{-1}$ fuel), with total OA on average 2.9 and 2.4 times higher than POA after aging for idling and driving $2 \mathrm{~S}$ scooters, respectively (Fig. 1, and Supplementary Table 2 ). In addition, substantial toxic aromatic emissions (up to $\sim 40 \%$ of emitted VOC volume for the scooters of this study) of benzene, toluene and $\mathrm{C} 2-\mathrm{C} 4$ alkylated benzenes, which are recognized SOA precursors ${ }^{10,12}$, are present in the exhaust. Among the aromatics, benzene is of particular concern due to its carcinogenicity. Levels in the raw $2 \mathrm{~S}$ scooter exhaust were as high as $300,000 \mathrm{~g} \mathrm{~m}^{-3}$ or 146 p.p.m.(v) from idling. The EU annual mean limit for the protection of human health is $5 \mu \mathrm{g} \mathrm{m}^{-3}$ (ref. 13), while the US National Institute for

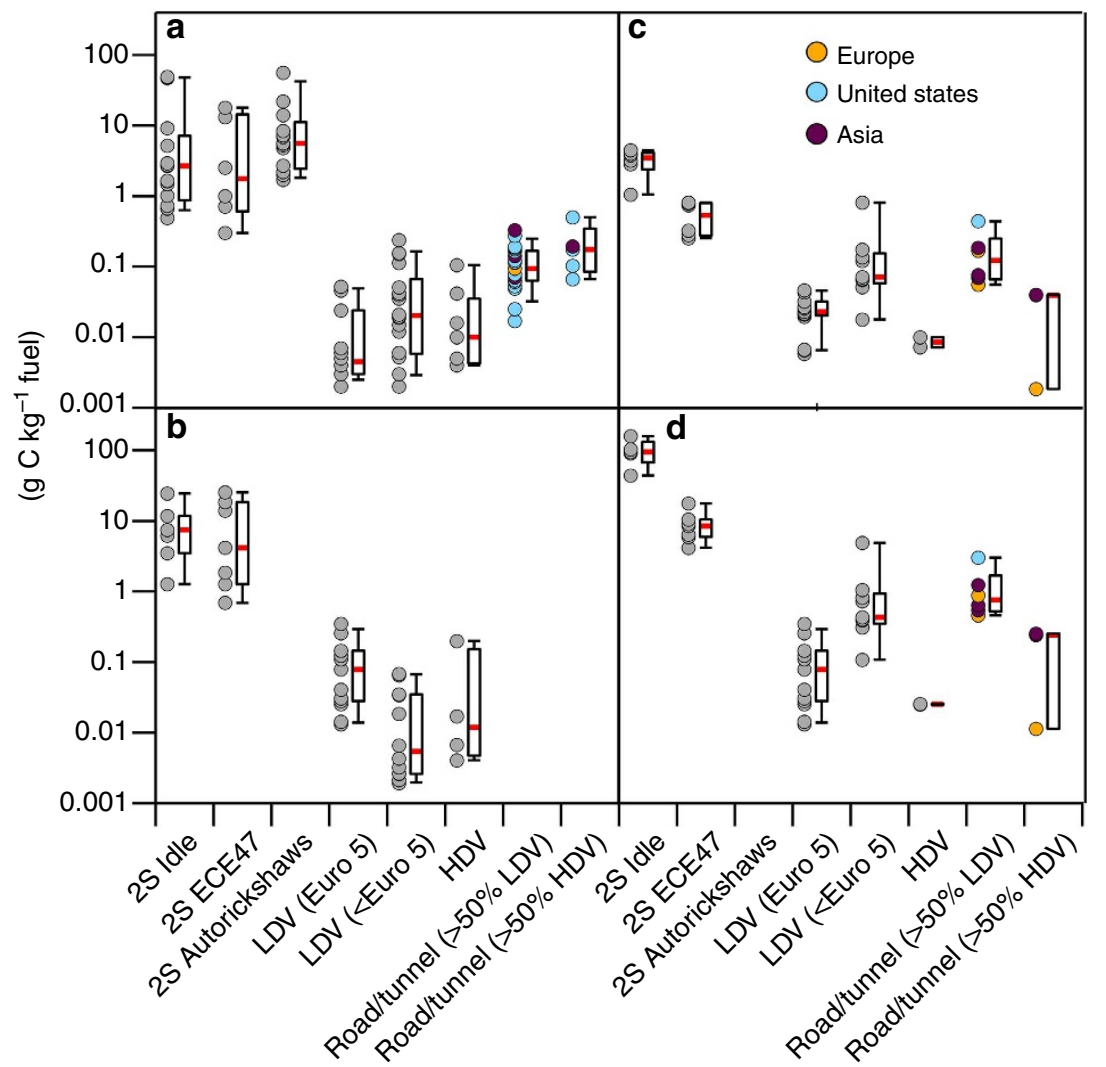

Figure 1 | Emission factors from scooters and other vehicles. EFs plotted as box-and-whiskers (median line, red; 25th and 75th percentile, box; 10th and 90th percentile, whiskers) of (a) POA, (b) aged OA (POA + SOA formation), (c) benzene and (d) light aromatics (benzene, toluene and C2-C4 alkylated benzenes). Points shown next to the box-and-whiskers are the individual data points, coloured depending on measurement region for ambient data. $2 S$ scooters (this study, $n=3$ ) were run in idle or during driving cycles (ECE47). Data on the other vehicles shown are from the literature (Supplementary Table 3) for light-duty and heavy-duty vehicles (LDVs and HDVs). LDVs data are further divided between vehicles meeting Euro 5 and those not meeting Euro 5, labelled < Euro 5 in parenthesis. Ambient data are split according to a contribution of HDVs to the data of higher than or lower than $50 \%$. Note that many of the higher ambient values are from older vehicle studies (Supplementary Table 3). 
Occupational Safety and Health recommends that workers wear special breathing equipment when exposed to benzene at levels exceeding 1 p.p.m. for $15 \mathrm{~min}$. Waiting in traffic behind a $2 S$ scooter, for example, at junctions and while the scooter is idling, may therefore be highly deleterious to health.

Secondary organic aerosol yields. The contribution of the aromatics to SOA formation was estimated by calculating an apparent aerosol yield, $y_{\text {apparent, }}$ assuming all SOA comes from aromatic precursors:

$$
y_{\text {apparent }}=C_{\mathrm{SOA}} / \sum_{\mathrm{i}} \Delta_{\mathrm{i}}
$$

where $\mathrm{C}_{\mathrm{SOA}}$ is the SOA produced $\left(\mu \mathrm{g} \mathrm{m}^{-3}\right)$ for a given mass change in aromatic $\mathrm{i}\left(\Delta_{\mathrm{i}}, \mathrm{i}=\right.$ benzene, toluene or $\mathrm{C} 2-\mathrm{C} 4$ alkylated benzenes). Apparent yields closely match average concentrationweighted literature aromatic SOA yields ${ }^{10}$ (Fig. 2a, Supplementary Note 1) for idling, complete ECE47 driving cycles and ECE47 phase one (Ph1), indicating that most SOA is from aromatic precursors (Fig. 2a). SOA from ECE47 phase two $(\mathrm{Ph} 2)$ alone is underestimated by equation (1), suggesting SOA production from unidentified compounds, emitted by the hot engine. Note that the total emission during a full cycle is dominated by $\mathrm{Ph} 1$, that is, by cold engine emissions. Furthermore, a 'Van Krevelen diagram' illustrates the aging of $2 \mathrm{~S}$ scooter emissions, from oxygen to carbon $(\mathrm{O}: \mathrm{C}) \sim 0$ to $\mathrm{O}: \mathrm{C} \sim 0.6$. This elemental composition is consistent with that of previously observed SOA from aromatic precursors ${ }^{14}$ (Fig. $2 \mathrm{~b}$ ). We therefore conclude that SOA formation from $2 S$ scooter emissions is likely from the oxidation of aromatics, in contrast to diesel SOA, which is predominantly from other precursors ${ }^{15}$.

Comparison to other vehicle types and ambient data. Figure 1 also shows laboratory and ambient measurements of POA, light aromatic and benzene EFs from passenger cars and trucks (Supplementary Table 3). Ambient data are from roadside/tunnel measurements in the US, EU and Asia, and are split according to the fraction of light-duty and heavy-duty vehicles (LDVs and HDVs, respectively) at the measurement site. Note that the general trend is for lower EFs in newer studies, consistent with improvements in emission controls. Also shown are data from Indian in-use $2 \mathrm{~S}$ autorickshaws for comparison to the European scooters of this study. Caution is required in such a comparison; however, although similar (both have $2 \mathrm{~S}$ engines), these are a different vehicle class and were furthermore tested during a different driving cycle. In general, ambient EFs from Asian vehicles are in the same range as European and US vehicles, while emissions from in-use $2 S$ rickshaws are slightly higher than from the European scooters of this study. POA emissions from $2 S$ scooters are on average around 20 (maximum 2,780) times higher than ambient (light-duty dominant) values, and aged OA emissions on an average 53-771 times higher than laboratory studies on other vehicle types. It should be noted that absolute aerosol concentrations can influence EFs: higher measurement concentrations would lead to higher $\mathrm{EFs}^{15}$. SOA formation is most significant from idling scooter emissions, while smaller at higher engine loads. However, POA emissions are higher under the latter conditions, and the aggregate POA $+\mathrm{SOA}$ emission at high load is comparable with that from idling.

Reactive oxygen species. We also examined the health implications of the $2 \mathrm{~S}$ scooter SOA (other than those from the mass increase) using online measurements of particle-bound, water soluble reactive oxygen species (ROS) ${ }^{16}$, which are linked to negative health effects ${ }^{17}$. ROS are undetectable in POA, but
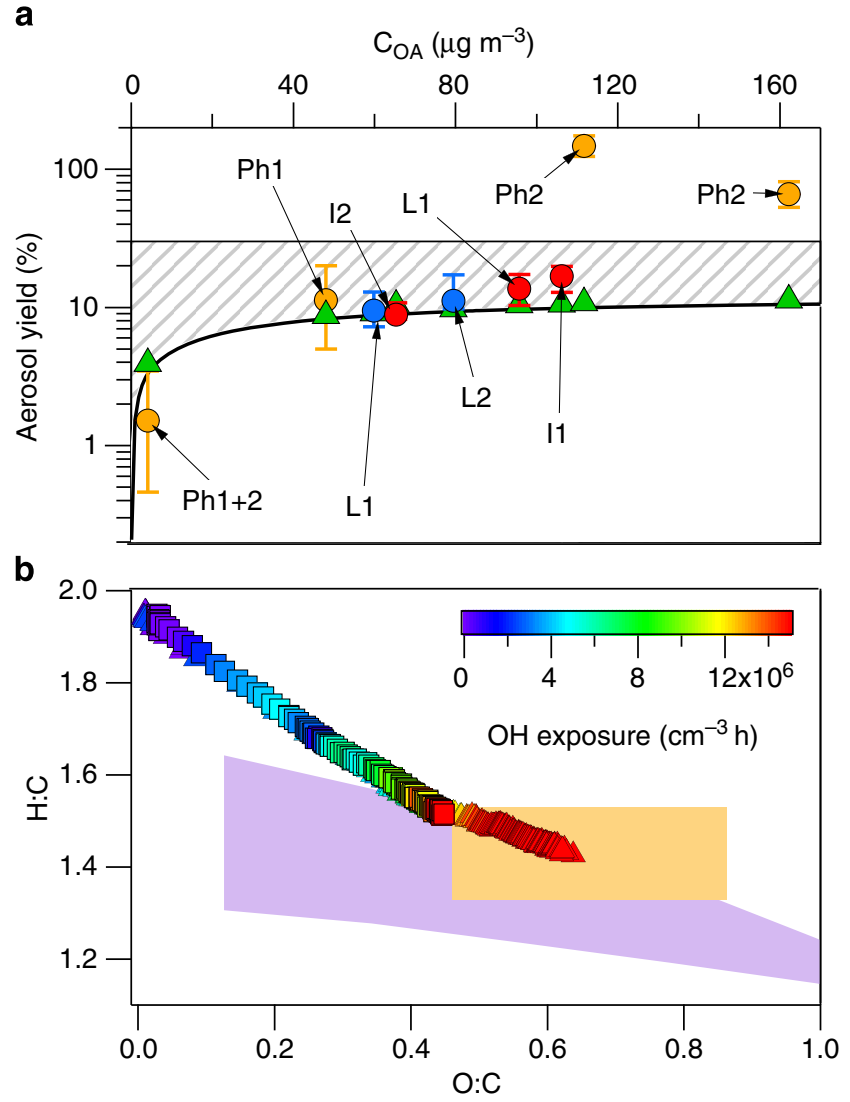

Figure 2 | Contribution of aromatic oxidation to two-stroke scooter secondary aerosol formation. (a) Apparent SOA mass yields, $y_{\text {apparent }}$ (equation (1)), as a function of suspended $\mathrm{OA}$ concentration $\left(\mathrm{C}_{\mathrm{OA}}\right)$. Error bars show the sensitivity of $y_{\text {apparent }}$ to the chamber wall-loss factor, \pm one s.d. $y_{\text {apparent }}$ for a Euro 1 and two Euro 2 2S scooters are shown in red, blue and orange, respectively. $\mathrm{Ph} 1$ and $\mathrm{Ph} 2$ are the first and second phases of the ECE47 driving cycle, I and L refer to idling and simulated low power, respectively. A predicted yield, concentration-weighted, for the mixture of all aromatics (Supplementary Note 1), is given in green triangles. The shaded region denotes the range between maximum (low $\mathrm{NO}_{X}$ ) and minimum (high $\mathrm{NO}_{X}$ ) SOA yields for $m$-xylene, a major aromatic constituent of gasoline. (b) Elemental ratios of OA emissions for the Euro 1 (squares) and a Euro 2 (triangles) scooter as a function of photochemical age. Elemental ratios observed for xylene $e^{13}$ and ambient ${ }^{31}$ SOA are shown, orange and purple, respectively.

accounts for $0.5-1 \%$ carbon in the aged OA, suggesting that PM emissions initially become increasingly toxic with aging (Fig. 3). Increasing ROS is consistent with the increased O:C ratio of the aerosol and in line with a previous study showing increased oxidative potential with aging for $2 \mathrm{~S}$ scooter emissions, albeit at aerosol and oxidant loadings much higher than under ambient conditions $^{18}$. After $1-2 \mathrm{~h}$ of irradiation, ROS stabilizes or decreases, as reported previously for organic peroxides, likely due to decomposition processes ${ }^{19,20}$.

\section{Discussion}

There are likely several reasons for these relatively large $\mathrm{OA}$ and aromatic emissions from $2 S$ scooters. First, $2 S$ engines, unlike four-stroke (4S), require addition of lubricant oils to the fuel, some of which is emitted in the exhaust. Second, during the $2 S$ engine cycle some of the fresh fuel/air mixture passes directly through the engine ${ }^{21}$, increasing VOC emissions, which may 
explain the high SOA formation. Third, scooters generally utilize 'rich combustion' (low-air/fuel ratio), improving drivability while producing higher $\mathrm{CO}, \mathrm{VOC}$ and $\mathrm{PM}$ emissions (but lower $\mathrm{NO}_{X}$ ). Accordingly, the VOC emissions measured here, in particular aromatics as found in raw gasoline, are also on average 124 and 11 times higher from idling and driving $2 \mathrm{~S}$ scooters, respectively,

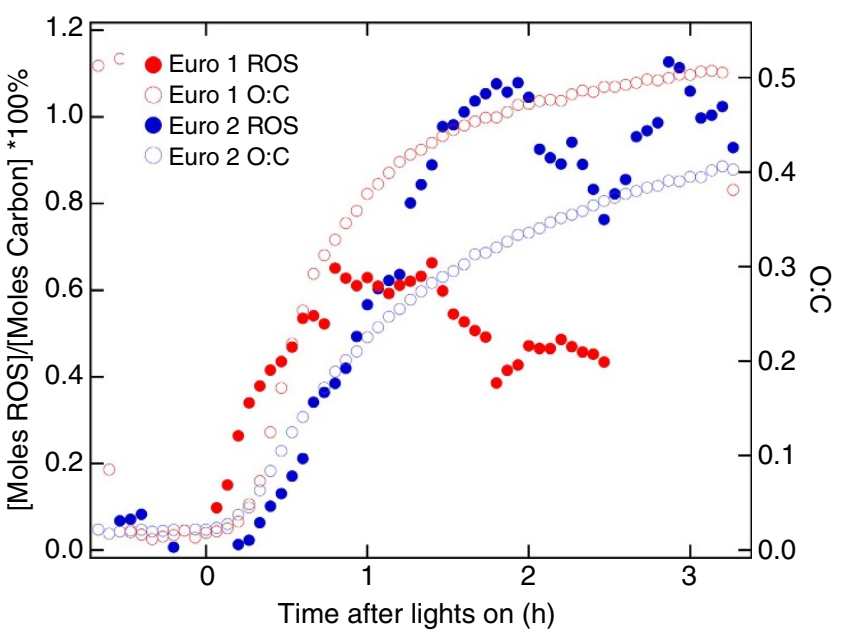

Figure 3 | Reactive oxygen species in two-stroke scooter emissions. The percentage of water soluble reactive oxygen species (ROS) and elemental $\mathrm{O}: \mathrm{C}$ ratios of organic aerosol as a function of time after lights on in the smog chamber from Euro 1 (red) and Euro 2 (blue) 2S scooter exhaust emissions. ROS concentration measured in moles hydrogen peroxide equivalents is normalized to the molar organic carbon concentration per $\mathrm{m}^{3}$ inside the smog chamber to give a percentage. compared with those from other vehicles. Finally, scooter aftertreatment systems are inherently inefficient due to their relatively small size and longer light-off times.

Precise estimation of a relative contribution to vehicular PM and aromatics from $2 S$ scooters is difficult, since vehicle regulations vary by country. Another complication arises from the possibility of large contributions to OA from a small number of super-polluting vehicles (of all types). However, many scooters will likely fall into this super-polluting category, especially as a considerable number of scooters are in operation in some regions without any form of emissions control (note that all scooters presented in this study are equipped with two-way oxidation catalysts, which reduce emissions of carbon monoxide and VOCs) and because emissions may be further exacerbated by poor maintenance and tampering, rife for scooters ${ }^{22}$. Furthermore, ambient data in Fig. 1 likely include a number of such super-polluting vehicles. Therefore, our results suggest that $2 \mathrm{~S}$ scooters are 'asymmetric polluters' of OA and aromatics compared with other vehicles. Using the average $2 \mathrm{~S}$ scooter $\mathrm{EF}$ (ECE47 driving cycle) in Fig. 1 suggests that $2 S$ scooters contribute to around $60 \%$ of roadside POA in Bangkok, where they account for $10 \%$ of fuel consumption (Fig. 4). In a more extreme case (comparing the 75th percentile for scooters and 25th percentile for ambient light-duty dominated), $2 \mathrm{~S}$ scooters would contribute over $96 \%$ to roadside POA. Note that these values are based on the European scooters of this study. As Fig. 1 shows, emissions from some in-use Asian $2 S$ vehicles may be higher, by a factor of three. Since other Asian vehicles are not expected to be more polluting based on Fig. 1, higher emissions from in-use Asian $2 S$ vehicles would strengthen our conclusion that $2 S$ scooters dominate urban pollution in the region.

Estimation of contributions to aged $\mathrm{OA}$ is more difficult as vehicular SOA has not been systematically quantified under

a

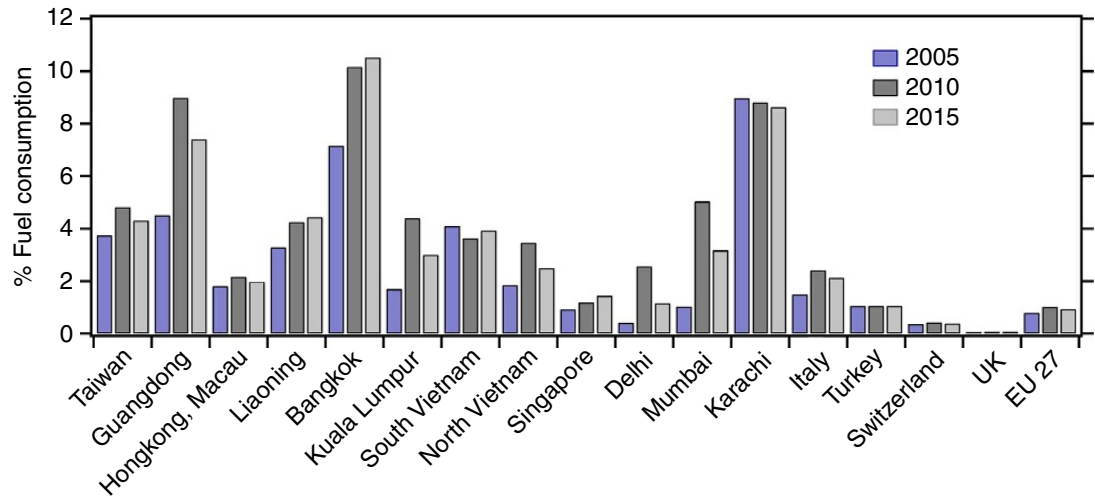

b

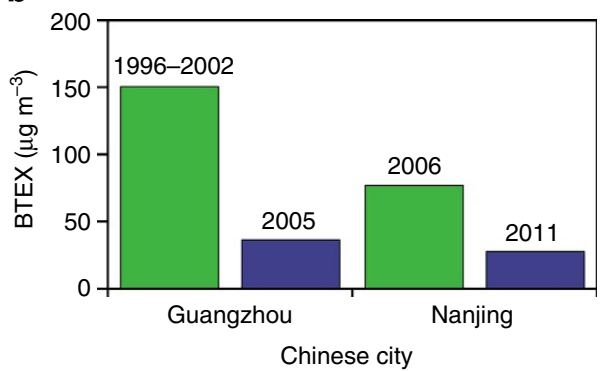

C

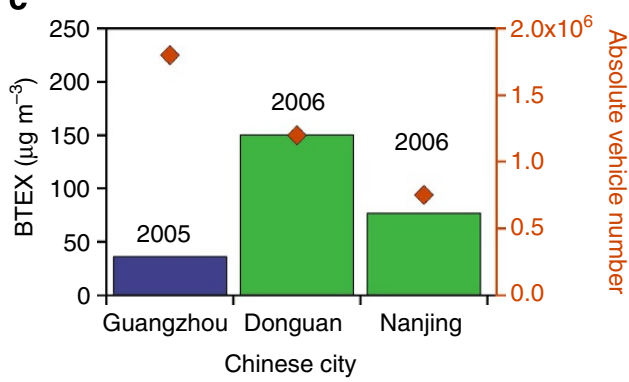

Figure 4 | Ambient and model data on two-stroke scooters. (a) Share of total fuel consumption by 2S scooters in 2005, 2010 and 2015 from the Greenhouse gas Air pollution Interactions and Synergies, GAINS, model ${ }^{11}$. (b) Roadside benzene, toluene, ethyl-benzene and xylene (BTEX) before (green) and after (blue) banning/restricting $2 \mathrm{~S}$ scooters in two Chinese cities (c) Roadside BTEX and number of all vehicles in three Chinese cities, before (green) and after (blue) banning/restricting $2 \mathrm{~S}$ scooters. 
ambient conditions. However, smog chamber measurements suggest average-aged OA contributions to ambient vehicular PM of $85 \%$ (comparing with LDVs meeting Euro 5) or 98\% (comparing with LDVs meeting less than Euro 5) from $2 \mathrm{~S}$ scooters. Meanwhile, in the EU, $2 \mathrm{~S}$ scooters consume only $1 \%$ of vehicle fuel, Fig. 4. Even with these low numbers, scooters may be the major source of some of the vehicle-related pollutants, especially in Southern Europe, and our data suggest that reducing the numbers of these vehicles would cost-effectively mitigate vehicle $\mathrm{OA}$ and aromatic emissions, given the alternatives available (electric and 4 S). In this regard China has taken the lead, banning or restricting scooters in many cities since the late $1990 \mathrm{~s}^{23}$, leading to large decreases in the traffic-related aromatic emissions in some Chinese cities (Fig. 4b). Strikingly, roadside aromatics are now higher in Dongguan, where scooters are not banned, than $60 \mathrm{~km}$ away in Guangzhou, even though the traffic volume is much higher in Guangzhou (Fig. 4c). This result is statistically significant: year-to-year benzene, toluene, ethylbenzene and xylene concentrations in Guangzhou were $229 \mathrm{\mu g} \mathrm{m}^{-3}$ in $1996,244 \mathrm{\mu g} \mathrm{m}^{-3}$ in $1999,290 \mathrm{\mu g} \mathrm{m}^{-3}$ in 2000 and $150 \mu \mathrm{g} \mathrm{m}^{-3}$ in 2002 , average $228 \pm 68$ versus $37 \mu \mathrm{g} \mathrm{m}^{-3}$ after the scooter ban in 2005, for example. Benzene, toluene, ethyl-benzene and xylene concentrations for Guangzhou and other cities reported in the literature are given in Supplementary Table 4.

Our data suggest that $2 \mathrm{~S}$ scooters are a significant, and in many cities the largest, source of vehicular PM and toxic SOA and aromatic hydrocarbons, despite being a relatively small fraction of the total fleet. Therefore, given the alternative technologies available, restrictions on $2 S$ scooters, already implemented in China, could improve air quality in many cities around the globe.

\section{Methods}

Measurement campaigns. We combine results from two measurement campaigns where $2 \mathrm{~S}$ scooter exhaust was injected through a heated inlet into smog chambers $^{3,24,25}$ to produce SOA via photochemistry. During the first study, an in-use Euro 1 (E1) and a new Euro 2 (E2a) 2S scooter were run in idle or simulated low power. During the second campaign, emissions from a different Euro $22 \mathrm{~S}$ scooter (E2b) were sampled during ECE47 driving cycles $^{26}$. Supplementary Table 5 provides specifications of these vehicles. European (exhaust) emission standards are shown in Supplementary Table 1. Average $\mathrm{OH}$ concentrations were $\sim 5 \times 10^{6} \mathrm{~cm}^{-3}$. OH concentrations were determined from the decay of a nine times deuterated butanol (butanol-D9, 98\% Aldrich) tracer as measured using a quadrupole proton transfer reaction mass spectrometer (idling $2 \mathrm{~S}$ scooters) or proton transfer reaction time-of-flight mass spectrometer (Ionicon Analytik, driving cycle $2 \mathrm{~S}$ scooters), see also ref. 27.

Estimation of the $\mathbf{N O}_{\boldsymbol{x}}$ regime during experiments. Experiments were under 'high $\mathrm{NO}_{x}$ ' conditions, which we define as the chemical regime where the main reactions of peroxy radicals $\left(\mathrm{RO}_{2}\right)$ are with $\mathrm{NO}$ rather than other peroxy radicals (self-reaction, or reaction with hydroperoxy radicals). An estimate of the ratio of the $\mathrm{RO}$-forming reactions $\left(\mathrm{RO}_{2}+\mathrm{NO}\right)$ versus peroxide-forming reactions $\left(\mathrm{RO}_{2}+\right.$ $\mathrm{RO}_{2}, \mathrm{RO}_{2}+\mathrm{HO}_{2}$ ) is possible for experiments conducted on idling scooters at the Paul Scherrer Institute chamber, instrumentation for which includes a $\mathrm{NO}_{X}$ monitor equipped with a 'blue light converter' (ensuring $\mathrm{NO}_{X}$ is truly measured as $\mathrm{NO}_{2}+\mathrm{NO}$ ). Figure $5 \mathrm{~b}$ shows the measured concentrations of $\mathrm{NO}$ and $\mathrm{O}_{3}$, from an experiment conducted on 22 November 2010. This experiment was typical, with an initial VOC: $\mathrm{NO}_{X}$ ratio of around 50 and continuous addition of NO during photochemical aging.

The concentration of $\mathrm{NO}$ as a function of time $t$ is given by:

$$
\frac{\mathrm{d}[\mathrm{NO}]}{\mathrm{d} t}=j_{\mathrm{NO} 2}\left[\mathrm{NO}_{2}\right]-k_{1}[\mathrm{NO}]\left[\mathrm{O}_{3}\right]-k_{2}[\mathrm{NO}]\left[\mathrm{RO}_{2}+\mathrm{HO}_{2}\right],
$$

Where $j_{\mathrm{NO} 2}$ is the photolysis rate of $\mathrm{NO}_{2}$ in the smog chamber $\left(0.01 \mathrm{~s}^{-1}\right)$ and $k_{1}\left(1.8 \times 10^{-14} \mathrm{~cm}^{3}\right.$ molecule $\left.^{-1} \mathrm{~s}^{-1}\right)$ and $k_{2}\left(7.7 \times 10^{-14} \mathrm{~cm}^{3}\right.$ molecule $\left.{ }^{-1} \mathrm{~s}^{-1}\right)$ are the reaction rate constants for $\mathrm{NO}$ with $\mathrm{O}_{3}$ and peroxides $\left(\mathrm{CH}_{3} \mathrm{O}_{2}\right)$ at $298 \mathrm{~K}$, respectively. Assuming a steady state of $\mathrm{NO}$ (only an approximation, Fig. 5 indicates this point is not reached until around $15 \mathrm{~h}$ of $\mathrm{OH}$ exposure (at $\mathrm{OH}=10^{6}$ molecules $\left.\mathrm{cm}^{-3}\right)$ ), equation (2) can be written:

$$
\left[\mathrm{RO}_{2}+\mathrm{HO}_{2}\right]=\frac{j_{\mathrm{NO} 2}\left[\mathrm{NO}_{2}\right]-k_{1}[\mathrm{NO}]\left[\mathrm{O}_{3}\right]}{k_{2}[\mathrm{NO}]} .
$$

Equation (3) suggests NO concentrations at least an order of magnitude higher than $\mathrm{RO}_{2}+\mathrm{HO}_{2}$ (for example, 14 times higher at $\mathrm{OH}=10 \times 10^{6}$ molecules $\mathrm{cm}^{-3} \mathrm{~h}$ ) during the experiment, based on concentrations measured inside the chamber (Fig. 5).

The branching ratio $r$ between the $\mathrm{RO}_{2} / \mathrm{HO}_{2}$ reactions with $\mathrm{NO}$ versus other with peroxides (Fig. 5a) is determined using

$$
r=\frac{k_{2}[\mathrm{NO}]}{k_{3}\left[\mathrm{HO}_{2}+\mathrm{RO}_{2}\right]},
$$

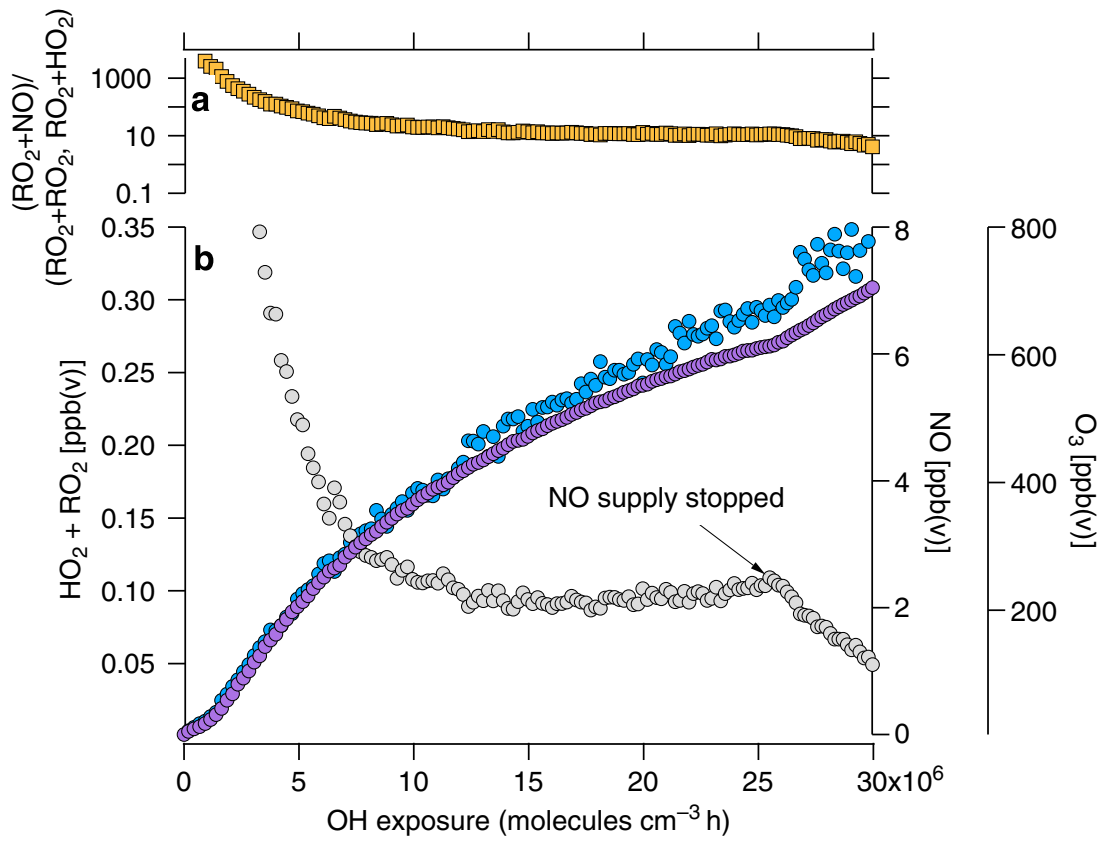

Figure 5 | Estimation of $\mathbf{N O}_{\boldsymbol{x}}$ regime. (a) Calculated branching ratio between nitrate and peroxide reactions (orange squares) in the smog chamber during aging of emissions from an idling $2 \mathrm{~S}$ scooter and $(\mathbf{b})$ measured concentrations of ozone $\left(\mathrm{O}_{3}\right)$ (purple circles) and nitrogen monoxide (NO) (grey circles) as well as calculated peroxy radical $\left(\mathrm{HO}_{2}+\mathrm{RO}_{2}\right)$ (blue circles) concentrations. 
where $k_{3}$ is the reaction rate constant between $\mathrm{HO}_{2}$ and $\mathrm{CH}_{3} \mathrm{O}_{2}\left(7.7 \times 10^{-12} \mathrm{~cm}^{3}\right.$ molecule $e^{-1} \mathrm{~s}^{-1}$ ) at $298 \mathrm{~K}$. We assume that the concentration of $\mathrm{HO}_{2}$ and $\mathrm{RO}_{2}$ is the same.

Figure 5a illustrates that the NO pathway is dominant, by at least a factor of 20 until $\mathrm{OH}=10 \times 10^{6}$ molecules $\mathrm{cm}^{-3} \mathrm{~h}$, and by initially thousands of times higher, over the peroxide pathway. Since $r>>1$ we consider these experiments 'high $\mathrm{NO}_{X}$ '.

An estimation of $r$ during the tests on driving cycle emissions is complicated by the lack of an accurate $\mathrm{NO}_{X}$ instrument (that is, one equipped with a blue light converter). Furthermore, NO was only continuously added during the experiment where emissions were sampled from the cold phase (which featured the highest VOC: $\mathrm{NO}_{X}$ ratio of any experiment). However, given that the driving cycle tests generally produced higher NO emissions than the idling tests, and given that most fall on the yield curve in Fig. 2, we also assume $r>>1$, although we can not rule out that during some experiments the conditions change from high to low $\mathrm{NO}_{X}$. Although the VOC: $\mathrm{NO}_{X}$ ratios were high (around 50), our best estimate suggests that idling experiments were high $\mathrm{NO}_{X}$ throughout. Figure $5 \mathrm{~b}$ shows the measured concentrations of $\mathrm{NO}$ and $\mathrm{O}_{3}$, during the experiment.

Idling scooter experiments. Emissions were introduced into the $27 \mathrm{~m}^{3}$ Paul Scherrer Institute Teflon environmental chamber ${ }^{24}$. The external temperature of the scooter exhaust was monitored (Thermocouple type K, Messelemente) and after an initial warming period of several minutes (consisting of idling or applying low power) the emissions were injected only when the external exhaust temperature was stable at idle or at simulated low power. Supplementary Table 2 provides the operating conditions, smog chamber OA concentrations and aerosol EFs of this study used in Fig. 1.

OA was monitored with a high-resolution time-of-flight aerosol mass spectrometer (Aerodyne). Unity collection efficiency is assumed, since emitted particles likely consist of spherical oil-like droplets with low bounce. After an initial spike in the OA concentration following sample injection, a time of at least $20 \mathrm{~min}$ was allowed for equilibration. The concentration of OA after this point was taken as the initial POA emission. A battery of $80 \times 100 \mathrm{~W}$ ultraviolet black lights (ErgoLine 'Cleo Performance', Solarium lights), was used to initiate photooxidation and SOA formation. Experiments were carried out with a steady injection of NO $\left(<20 \mathrm{ml} \mathrm{min}^{-1}\right)$ whereby NO was maintained at around 2-3 $\mathrm{ppb}(\mathrm{v})$. Relative humidity inside the smog chamber was between $40-60 \%$ for all experiments, and temperature was maintained at $25{ }^{\circ} \mathrm{C}$.

OA was corrected for wall losses using

$$
\mathrm{OA}_{\mathrm{WLC}}(t)=\frac{\operatorname{OA}_{\mathrm{MEAS}}(t)}{\exp (-k t)}
$$

where $\mathrm{OA}_{\mathrm{WLC}}(t)$ and $\mathrm{OA}_{\mathrm{MEAS}}(t)$ are the wall-loss corrected and measured organic matter concentrations, respectively, as a function of time $t$, and $k$ is the first order mass-loss rate constant determined from an exponential fit of $\mathrm{BC}$ data.

VOCs inside the smog chamber were quantified with a quadrupole proton transfer reaction mass spectrometer, while carbon monoxide was quantified with a dedicated CO monitor (Aerolaser, CO-Monitor AL5002) and total gas-phase hydrocarbons were measured from the chamber using a flame ionization detector (FID, J.U.M model VE 7). Additional measurements at the tailpipe were performed by transferring emissions through a heated line $\left(191{ }^{\circ} \mathrm{C}\right)$ to a Fourier transformed infrared spectrometer (MKS Multigas analyser 2030) for online measurements (at $1 \mathrm{~Hz}$ ) of small hydrocarbons, nitrogen containing species $\left(\mathrm{NO}, \mathrm{NO}_{2}, \mathrm{~N}_{2} \mathrm{O}, \mathrm{NH}_{3}\right.$ and $\mathrm{HCN}$ ) and other oxygenated small organics (formaldehyde, acetaldehyde), as well as $\mathrm{CO}$ and $\mathrm{CO}_{2}$.

Online reactive oxygen species measurements. Online particle-bound ROS analysis utilized the fluorescence probe 2,7-dichlorofluorescein in solution. Particles were collected and continuously extracted on a wetted hydrophilic filter. The particle collector samples air at $51 \mathrm{~min}^{-1}$ and collects particles larger than aerodynamic diameter $50 \mathrm{~nm}$ with greater than $95 \%$ efficiency. Particles are collected and extracted in an aqueous solution of horseradish peroxidase $\left(0.5 \mathrm{U} \mathrm{ml}^{-1}\right)$ allowing immediate reaction of ROS on collection. The concentration of ROS is characterized following subsequent reaction of the oxidized horseradish peroxidase with 2,7 -dichlorofluorescein $(5 \mu \mathrm{M})$ for $10 \mathrm{~min}$ at $40^{\circ} \mathrm{C}$, yielding the fluorescent product DCF in the continuous flow set up. The concentration of 2,7-dichlorofluorescein is measured using fluorescence spectroscopy in a flow-through cell and calibrated to ROS concentration with hydrogen peroxide. ROS data in Fig. 3 are normalized to the total carbon $\mathrm{m}^{-3}$, determined from high-resolution fitting of aerosol mass spectrometer data, and presented as a percentage.

Driving cycle scooter experiments. The Paul Scherrer Institute mobile smog chamber $^{3}$ was deployed, and experiments conducted in a certified chassis dynamometer test cell (Vehicle Emissions Laboratories, Joint Research Centre of the European Commission, JRC-Ispra, Italy) ${ }^{28,29}$. Emissions from $2 \mathrm{~S}$ scooters were sampled at the tailpipe during full ECE47 driving cycles, during Ph1 only of the ECE47 (first four modules of the driving cycle, Ph1), and during Ph2 only of the ECE47 (final four modules of the driving cycle, $\mathrm{Ph} 2$ ). The emissions were transferred to the smog chamber via a heated inlet system $\left(150^{\circ} \mathrm{C}\right)$ and Dekati ejector dilutor. Ultraviolet lights were switched on after several minutes to initiate photochemistry. OA concentrations were measured with a high-resolution time-offlight aerosol mass spectrometer (Aerodyne), while black carbon was quantified with an aethalometer (AE33, Aerosol d.o.o.). The exponential decay rate of black carbon $k$ was used in equation (5) to correct for particle losses to the walls. Gasphase compounds were monitored with a proton transfer reaction time-of-flight mass spectrometer (Ionicon), while $\mathrm{CO}_{2}$ and $\mathrm{CO}$ were measured using a cavity ring down spectrometer (Picarro, G2401) and total hydrocarbons were measured with a flame ionization detector (Horiba, THC Monitor APHA-370).

Emission factor determination. EFs from both measurement campaigns (EF, $\mathrm{g} \mathrm{C} \mathrm{kg}^{-1}$ fuel), (see also Supplementary Table 3), were calculated using a carbon mass balance:

$$
\mathrm{EF}=\left(\frac{\mathrm{OC}}{C_{\mathrm{CO} 2}+C_{\mathrm{CO}}+C_{\mathrm{HC}}}\right) \cdot W_{\mathrm{C}},
$$

where $\mathrm{C}$ denotes carbon mass, and the subscripts $\mathrm{CO}_{2}, \mathrm{CO}, \mathrm{HC}$, carbon dioxide, carbon monoxide and hydrocarbon, respectively. $W_{\mathrm{c}}$ is the fuel carbon content ( 0.847 for gasoline).

For the idling scooter experiments, $C_{\mathrm{CO}}$ and $C_{\mathrm{CO} 2}$ were measured at the tailpipe using the Fourier transformed infrared spectrometer. $C_{\mathrm{HC}}$ was measured from the smog chamber and scaled-up to the tailpipe concentration using the dilution ratio $\mathrm{CO}_{\text {tailpipe }} / \mathrm{CO}_{\text {smog chamber. }}$ Meanwhile, for the driving cycles all concentrations were determined at the smog chamber.

Emission factors from the literature. Figure 1 and Supplementary Table 3 show EFs calculated from the literature. When available, EFs are given as reported. OA EFs measured in tunnels/roadside are assumed to consist purely of POA and are converted to EFs in units of $\mathrm{g} \mathrm{kg}^{-1}$ fuel using an organic matter to organic carbon ratio (OM:OC) of 1.2 (ref. 30). EFs given in units of $\mathrm{g} \mathrm{km}^{-1}$ are converted using the following fuel consumptions ( $\mathrm{km} \mathrm{kg}^{-1}$ ): Asia LDVs: 16.43; US LDVs: 14.93; EU LDVs: 18.20; Heavy-duty vehicles: 2.85. EFs measured during the Kansas City vehicle study are estimated by inserting per $\mathrm{km} \mathrm{EFs}$ into equation (6). SOA in Supplementary Table $3\left(\mathrm{~g} \mathrm{C} \mathrm{kg}^{-1}\right.$ fuel) is converted from units of $\mathrm{g} \mathrm{kg}^{-1}$ fuel using an OM:OC ratio of 2.0 (ref. 30). SOA formation from $2 \mathrm{~S}$ scooters is not available in the literature, but was estimated from emissions of aromatic hydrocarbons using a yield (see Supplementary Note 1 and Fig. 2) of 8.4\% (suspended OA concentration $50 \mu \mathrm{g} \mathrm{m}^{-3}$ ). Further notes to individual studies are also provided in Supplementary Table 3.

\section{References}

1. Dockery, D. W. et al. An association between air pollution and mortality in six US cities. New Engl. J. Med. 329, 1753-1759 (1993).

2. IPCC. Contribution of Working Group I to the Fourth Assessment Report of the Intergovernmental Panel on Climate Change (Cambridge University Press, 2007).

3. Platt, S. M. et al. Secondary organic aerosol formation from gasoline vehicle emissions in a new mobile environmental reaction chamber. Atmos. Chem. Phys. 13, 9141-9158 (2013).

4. Hallquist, M. et al. The formation, properties and impact of secondary organic aerosol: current and emerging issues. Atmos. Chem. Phys. 9, 5155-5236 (2009)

5. Nordin, E. Z. et al. Secondary organic aerosol formation from idling gasoline passenger vehicle emissions investigated in a smog chamber. Atmos. Chem. Phys. 13, 6101-6116 (2013).

6. Czerwinski, J., Comte, P. \& Reutimann, F. Nanoparticle Emissions of a DI 2-Stroke Scooter with Varying Oil and Fuel Quality. SAE transactions 114, 541-556 (2005).

7. Rijkeboer, R., Bremmers, D., Samaras, Z. \& Ntziachristos, L. Particulate matter regulation for two-stroke two wheelers: necessity or haphazard legislation? Atmos. Environ. 39, 2483-2490 (2005).

8. European Commission (EC). O.J.E.C. L67, 14-30 (2002).

9. Geivanidis, S. et al. Arisotle University (2008). Thessaloniki, available at http:// www.ec.europa.eu/enterprise/sectors/automotive/documents/calls-for-tenderand-studies/index_en.htm, last accessed 12 January 2014.

10. Ng, N. L. et al. Secondary organic aerosol formation from m-xylene, toluene, and benzene. Atmos. Chem. Phys. 7, 3909-3922 (2007).

11. Lan, T. T. N. \& Minh, P. A. BTEX pollution caused by motorcycles in the megacity of HoChiMinh. J. Environ. Sci. 25, 348-356 (2013).

12. Odum, J. R. et al. Aromatics, reformulated gasoline, and atmospheric organic aerosol formation. Environ. Sci. Technol. 31, 1890-1897 (1997).

13. European Commission (EC), Directive 2008/50/EC of the European Parliament and of the Council of 21 May 2008 on Ambient Air Quality and Cleaner Air for Europe, http://eur-lex.europa.eu/LexUriServ/LexUriServ.do?uri=OJ:L:2008: 152:0001:0044:EN:PDF (2008).

14. Chhabra, P. S., Flagan, R. C. \& Seinfeld, J. H. Elemental analysis of chamber organic aerosol using an Aerodyne high-resolution aerosol mass spectrometer. Atmos. Chem. Phys. 10, 4111-4131 (2010).

15. Robinson, A. L. et al. Rethinking organic aerosols: semivolatile emissions and photochemical aging. Science 315, 1259-1262 (2007). 
16. Fuller, S. J., Wragg, F. P. H., Nutter, J. \& Kalberer, M. Comparison of on-line and off-line methods to quantify reactive oxygen species (ROS) in atmospheric aerosols. Atmos. Environ 92, 97-103 (2014).

17. Donaldson, K. et al. Oxidative stress and calcium signaling in the adverse effects of environmental particles $\left(\mathrm{PM}_{10}\right)$. Free Radic. Biol. Med. 34, 1369-1382 (2003).

18. McWhinney, R. D., Gao, S. S., Zhou, S. \& Abbatt, J. P. Evaluation of the effects of ozone oxidation on redox-cycling activity of two-stroke engine exhaust particles. Environ. Sci. Technol. 45, 2131-2136 (2005).

19. Mertes, P., Pfaffenberger, L., Dommen, J., Kalberer, M. \& Baltensperger, U. Development of a sensitive long path absorption photometer to quantify peroxides in aerosol particles (Peroxide-LOPAP). Atmos. Meas. Tech. 5, 2339-2348 (2012)

20. Surratt, J. D. et al. Chemical composition of secondary organic aerosol formed from the photooxidation of isoprene. J. Phys. Chem. A 110, 9665-9690 (2006).

21. Spezzano, P., Picini, P. \& Cataldi, D. Contribution of unburned lubricating oil and gasoline-derived n-alkanes to particulate emission from non-catalyst and catalyst-equipped two-stroke mopeds operated with synthetic lubricating oil. J. Environ. Monit. 10, 1202-1210 (2008).

22. Santino, D., Picini, P. \& Martino, L. Particulate matter emissions from twostroke mopeds. SAE 2014, 4-10 (2001).

23. Yang, C. J. Launching strategy for electric vehicles: Lessons from China and Taiwan. Technol. Forecast. Soc. Change 77, 831-834 (2010).

24. Paulsen, D. et al. Secondary organic aerosol formation by irradiation of 1,3 5 -trimethylbenzene- $\mathrm{NOx}-\mathrm{H}_{2} \mathrm{O}$ in a new reaction chamber for atmospheric chemistry and physics. Environ. Sci. Technol. 39, 2668-2678 (2005).

25. Chirico, R. et al. Impact of aftertreatment devices on primary emissions and secondary organic aerosol formation potential from in-use diesel vehicles: results from smog chamber experiments. Atmos. Chem. Phys. 10, 11545-11563 (2010).

26. United Kingdom Transport Research Laboratory (TRL), A Reference Book of Driving Cycles for Use in the Measurement of Road Vehicle Emissions, http:// www.trl.co.uk/online_store/reports_publications/trl_reports/

cat_traffic_and_the_environment/report_a_reference_book_of driving_cycles_for_use_in_the_measurement_of_road_vehicle_emissions. htm (2009).

27. Barmet, P. et al. OH clock determination by proton transfer reaction mass spectrometry at an environmental chamber. Atmos. Meas. Tech. 5, 647-656 (2012).

28. Clairotte, M. et al. Online characterization of regulated and unregulated gaseous and particulate exhaust emission from two-stroke mopeds: a chemometric approach. Anal. Chim. Acta. 717, 28-38 (2012).
29. Adam, T. et al. Chemical characterization of emissions from modern twostroke mopeds complying with legislative regulation in Europe (EURO-2). Environ. Sci. Technol. 44, 505-512 (2010).

30. Aiken, A. C. et al. O/C and OM/OC ratios of primary, secondary, and ambient organic aerosols with high-resolution time-of-flight aerosol mass spectrometry. Environ. Sci. Technol. 42, 4478-4485 (2008).

31. Klaassen, G., Berglund, C. \& Wagner, F. The GAINS Model for Greenhouse Gases-Version 1.0: Carbon Dioxide $\left(\mathrm{CO}_{2}\right)$. IIASA Interim Report IR-05-53 (International Institute for Applied Systems Analysis (IIASA), Laxenburg, Austria, 2005).

\section{Acknowledgements}

This work was supported by the Swiss Federal Office for the Environment (FOEN), the Federal Roads Office (FEDRO), the Swiss National Science Foundation (Ambizione PZ00P2_131673, SAPMAV 200021_13016), the EU commission (FP7, COFUND: PSIFellow, grant agreement $n .^{\circ}$ 290605), the UK Natural Environment Research Council (NERC), the French Environment and Energy Management Agency (ADEME, Grant number 1162C00O2) and the Velux Stiftung, project 593.

\section{Author contributions}

Study design (S.M.P., A.S.H.P., M.C., A.A.Z., U.B., I.E.H.); experimental work, idling $2 S$ scooters (S.M.P., M.C., L.P., P.B., J.D., S.J.F.); experimental work, driving cycle $2 S$ scooters and other vehicles (S.M.P., I.E.H., J.G.S., M.C., A.A.Z., S.H., B.T.-R. S.M.P., R.S.-B.); data analysis, emission factors (S.M.P., S.M.P., I.E.H., M.C., A.A.Z., J.G.S., P.B., S.H., B.T.-R.); data analysis, reactive oxygen species (S.J.F.); data analysis, SOA yields (S.M.P.); literature data ambient BTEX (R.-J.H.); literature data ambient PM/aromatic (I.E.H.); writing of manuscript (S.M.P.); preparation of display items (S.M.P., S.M.P., R.-J.H.); data interpretation and editing of manuscript (S.M.P., M.C., I.E.H., S.M.P., R.-J.H., R.Z., R.C., C.A., J.D., L.P., A.S.H.P., M.K., N.M., U.B.); comments and discussion on the manuscript (all).

\section{Additional information}

Supplementary Information accompanies this paper at http://www.nature.com/ naturecommunications

Competing financial interests: The authors declare no competing financial interests.

Reprints and permission information is available online at http://npg.nature.com/ reprintsandpermissions/

How to cite this article: Platt, S. M. et al. Two-stroke scooters are a dominant source of air pollution in many cities. Nat. Commun. 5:3749 doi: 10.1038/ncomms4749 (2014) 